\title{
Valorização do produto de grupos produtivos de pequeno porte a partir de uma nova embalagem: o caso de uma em- balagem de farinha de mandioca
}

Eugenio Andrés Díaz Merino

Universidade Federal de Santa Catarina

merino@cce.ufsc.br

Leila Amaral Gontijo

Universidade Federal de Santa Catarina

leila@deps.ufsc.br

Giselle Schmidt Díaz Merino

Universidade Federal de Santa Catarina

gisellemerino@gmail.com
Bruna Pasquali Plentz

Universidade Federal de Santa Catarina

bruplentz@gmail.com

Douglas da Silva

Universidade Federal de Santa Catarina

douglas.sm3@gmail.com

\section{Resumo}

A necessidade de valorizar a produção e consequentemente os produtos gerados por pequenos produtores vem requerendo o envolvimento de diversas áreas, dentre elas o design. Por meio da criação de identidades visuais (marcas) e embalagens, o design vem auxiliando estes produtos na sua inserção no mercado. Desta forma, este artigo objetiva apresentar o desenvolvimento de uma embalagem para o acondicionamento de farinha de mandioca Premium para ser levada à mesa, tendo como base aspectos culturais e de identificação do produto para uma das cooperativas atendidas. A metodologia utilizada se dividiu em duas fases, sendo a primeira de levantamento de informações sobre a problemática e uma segunda, de cunho prático, se utilizando do Guia de Orientação para o Desenvolvimento de Projetos (GODP) tendo como resultados três propostas. Finalmente foi possível identificar a importância da inserção da Gestão de Design para alcançar a valorização por meio da diferenciação e aumento de competitividade na Cooperativa beneficiada.

Palavras-chave: Gestão de Design. Design de Produto. Agricultura familiar. Farinha de mandioca. Embalagem.

\section{Boosting the value of proucts by small manufacturing businesses in santa catarina: the manioc flour packaging case}

\section{Abstract}

The urge to highlight the value of production and, consequentially, the products generated by small manufacturing businesses, has revealed the need for a deeper involvement by areas such as design. Through 
the creation of visual identities (brands) and packaging, the design has been assisting the management of these products when they get inserted into the market. Thus, this article means to present the development of packaging for the Premium manioc flour, taking cultural and product identification aspects into consideration. It comes as part of the extension project named "Boosting and protecting the production by small manufacturing businesses: Cooperatives in Santa Catarina". The methodology used was divided into two phases, the first being an informative survey and the second the project development, using the Guidebook for the Development of Products (GODP), and the outcome came in three proposals. It was possible to identify the importance of inserting the design geared towards boosting the value of products, in a culturally appealing way

Keywords: Product Design. Familiar agriculture. Manioc flour. Wrapping. Design Management. Usability. Ergonomics.

\section{INTRODUÇÃO}

Atualmente, a despeito de representar mais de 10\% do PIB (Produto Interno Bruto) brasileiro, a agricultura familiar vem sucumbindo ante a necessidade de seus produtores se submeterem às ofertas e exigências do mercado que, cada vez mais, se alinha às características e desejos de grandes conglomerados de produção rural. Nos últimos anos, a produção rural familiar no Brasil vem se reestruturando sob a forma de cooperativas, de maneira que os efeitos negativos provocados pelas exigências de mercado possam ser minimizados. Nesse contexto, vislumbrando-se a tríade de competitividade, diferenciação e sustentabilidade, pôde-se propor o design como uma ferramenta altamente transformadora e capaz de convergir as habilidades e necessidades individuais de diversos produtores familiares para um objetivo comum a todos os cooperados (MERINO, 2010).

Tendo-se em conta o cenário da produção familiar brasileira, dá-se particular destaque ao estado de Santa Catarina, localizado no Sul do país, em que 87\% dos estabelecimentos agropecuários são classificados como sendo da agricultura familiar. Esse valor faz de Santa Catarina uma das unidades da federação com os maiores percentuais de agricultores familiares do Brasil (EPAGRI / CEPA, 2009 - 2010). Dessa forma, objetiva-se apresentar o projeto de desenvolvimento de uma embalagem para a farinha de mandioca, tendo como base aspectos culturais e de identificação do produto para uma das cooperativas atendidas, nesse caso, a COOPERLAGOS.

A mandioca é um tubérculo comestível de origem brasileira que, mesmo tendo seu consumo já disseminado em diversos locais no mundo, sobretudo na América Latina e na África, apresenta baixo valor agregado (MINISTÉRIO DA AGRICULTURA, PECUÁRIA E ABASTECIMENTO, 2011). Um dos principais subprodutos da mandioca é a farinha, de valor agregado igualmente baixo. Normalmente oferecida em frágeis pacotes plásticos, a farinha de mandioca é um alimento bastante popular na culinária brasileira, de modo que, a partir dessa constatação, observou-se a possibilidade de desenvolver uma ação estratégica de design sobre tal produto, objetivando sua valorização por meio do acondicionamento e proteção proporcionados pela sua embalagem, que, nesse caso, teria características particulares de acondicionamento e dosagem.

A atividade de criação da embalagem foi realizada para o projeto de extensão da Universidade Federal de Santa Catarina intitulado "Valorização e Proteção da Produção de Pequenos Produtores: Cooperativas em Santa Catarina”. Esse projeto também é parte dos resultados alcançados por um projeto internacional denominado "Valorização da Produção de Grupos Produtivos de Pequeno Porte Vinculados a Sua Origem, Com Base na Competitividade, Diferenciação e Sustentabilidade", que contou com a participação da Venezuela, Peru e Brasil e com o apoio de CNPq e FAPESC.

Assim, tem-se como objetivo o atendimento de uma demanda prática do design quanto à identificação de produtos da agricultura familiar, em específico com foco de ação na COOPERLAGOS, no que diz 
respeito à farinha de mandioca produzida pela cooperativa. Além do desenvolvimento da identidade visual (marca), entende-se por demanda prática do design sua aplicação em diferentes produtos, como a embalagem, que tem como função prática expor, transportar, proteger, comercializar e servir o produto em questão. Ainda com relação à embalagem, a consideração de aspectos culturais e históricos no seu projeto se torna importante, no sentido de valorizar tanto o produto quanto a produção.

A partir de estudos e pesquisas realizadas orientou-se o projeto para a concepção de uma embalagem de farinha de mandioca que pudesse ser levada à mesa. Tal embalagem deveria ser refilável, permitindo, assim, sua reutilização, bastando apenas repor seu conteúdo interno, e apresentando ainda, como aspecto funcional fundamental, uma tampa dosadora capaz de facilitar o consumo do produto. Por fim, a estética da embalagem deveria também sintetizar parte dos aspectos históricos e culturais característicos dos produtos provenientes da mandioca e de sua produção artesanal.

Justifica-se este projeto por meio da introdução do design como fator fundamental de competitividade, compreendendo uma maneira inovadora de se apresentar um produto que, convencionalmente, costuma ser banalizado e desvalorizado por sua própria embalagem. Denota-se ainda a valorização das questões semânticas e culturais inerentes a produtos derivados da mandioca, buscando não apenas valorizá-los, mas também apresentá-los a todo um grupo de consumidores que não consideravam tais aspectos. Ademais, busca-se dar valor ao produto introduzindo-se, por meio de sua própria embalagem, elementos facilitadores e dinamizadores de seu uso. Em suma, propõe-se uma relação otimizada entre produto e usuário, com potenciais reflexos positivos na sua inserção no mercado.

O caso apresentado exemplifica de maneira prática como o design é capaz de incorporar inovação a produtos tradicionais, porém economicamente subestimados, propondo uma abordagem que vislumbra os aspectos da produção do produto, inclusive as pessoas envolvidas no processo, podendo promover, assim, ganhos socioeconômicos a todo um vasto grupo de pessoas e ressaltando a importância de um produto pouco reconhecido e valorizado, porém fortemente enraizado na cultura de um povo. Como possível resultado da ação de design, pode-se relatar ainda melhorias na competitividade do produto.

\section{Material e Métodos}

O percurso metodológico foi dividido em duas fases: a primeira de cunho teórico e a segunda de cunho prático. Na primeira fase, foram realizados levantamentos técnicos, históricos, culturais, entre outros, que serviram de base para a compreensão dos elementos estruturais do projeto - grupos produtivos de pequeno porte, agricultura familiar, a mandioca e a farinha —, juntamente com levantamentos relacionados a consumo e formas de acondicionamento, obtidos por meio da aplicação de questionários on-line utilizando a ferramenta para geração de formulários disponibilizada pelo Google Docs. Essa fase utilizou outras pesquisas já realizadas pelos autores deste projeto relacionadas à farinha de mandioca premium ${ }^{1}$.

Na segunda fase, de cunho prático, foram desenvolvidas as embalagens seguindo o Guia de Orientação para o Desenvolvimento de Projetos (GODP) (MERINO et al., 2011), desenvolvido a partir de literaturas de design e de áreas correlatas e, sobretudo, a partir da experiência obtida pelo Núcleo de Gestão de Design da Universidade Federal de Santa Catarina (UFSC) em projetos e desenvolvimento de teses. O GODP parte da proposta de integração e inovação, integrando de maneira eficaz as áreas envolvidas no desenvolvimento de produtos e valorizando os envolvidos no processo, tornando-se, assim, uma ferramenta capaz de promover inovação e competitividade a um projeto.

1 Farinha premium: farinha de mandioca em embalagem para ser levada à mesa. Relatório de projeto desenvolvido por Giselle Merino, Carlos A. Fernandes, Celso R. Salazar Valentin, Tanatiana Guelbert e Thaiana P. do Anjos na disciplina de Desenvolvimento de Produto II do PPGEP/UFSC, sob orientação do Prof. Dr. Marcelo Gitirana, no ano de 2010. 


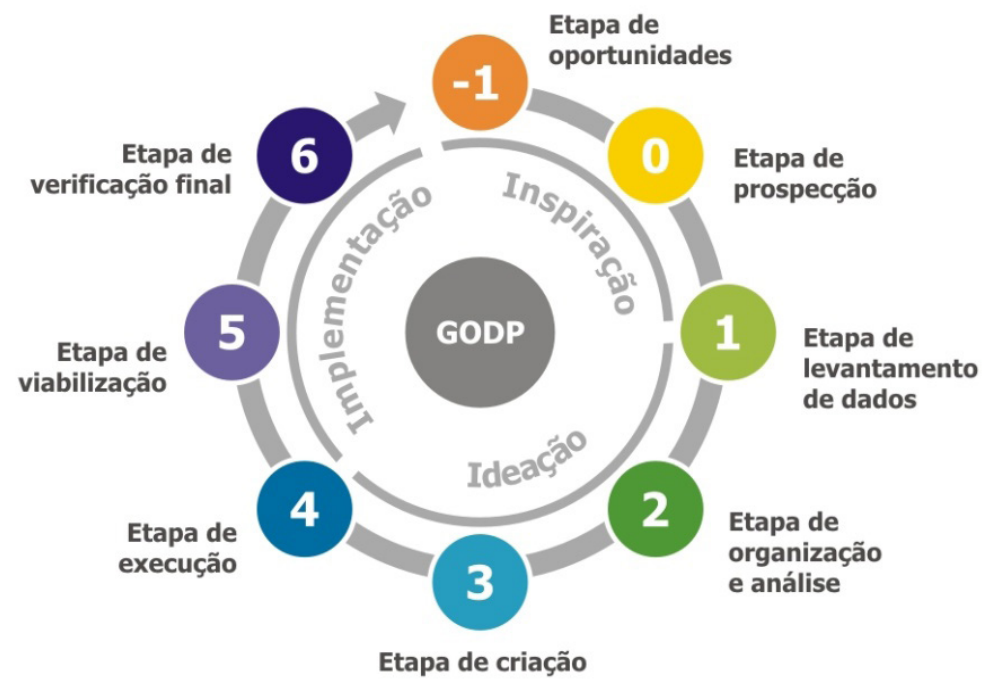

Figura 1 - GODP

Fonte: Merino (2011)

Como pode ser observado na Figura 1, o GODP apresenta três momentos no processo de desenvolvimento: inspiração, ideação e implementação. Os três momentos desdobram-se em etapas: a etapa (-1) visa verificar as oportunidades do mercado, conforme mercados e setores do produto a ser avaliado; na etapa (0), são definidas demanda e problemática central do projeto; na etapa 1, são desenvolvidas as definições de projeto a partir de um levantamento de dados; na etapa 2, os dados anteriormente obtidos são organizados e analisados; na etapa 3, inicia-se a etapa de criação, na qual são geradas as alternativas preliminares; a etapa 4 é a de execução, em que são desenvolvidos protótipos do projeto; a 5 é a de viabilização, em que o produto é testado em condições reais e pesquisas são realizadas junto a consumidores; na etapa 6, por fim, ocorre a verificação do projeto, considerando aspectos como sustentabilidade, além dos impactos econômicos e sociais do projeto.

Justifica-se o uso do GODP tendo em vista que suas aplicações, segundo Merino, Gontijo e Merino (2011), "têm resultado em produtos que encontram amparo no processo formativo (dimensão acadêmica), no processo investigativo (dimensão pesquisa) e no processo aplicado real (dimensão extensão)", convergindo para as necessidades do projeto aqui descrito.

\section{RESULTADOS E ANÁLISE}

O projeto aqui apresentado foi desenvolvido em conjunto com a Cooperativa dos Produtores Familiares e Pescadores Artesanais da região dos Lagos Sul Catarinense (COOPERLAGOS), constituída por vinte e quatro cooperados, abrangendo sete municípios (Paulo Lopes, Imaruí, Penha, Garopaba, Imbituba, Laguna e Criciúma), cujas atividades desenvolvidas variam desde a produção de carnes bovinas, suínas e de aves, passando pelo cultivo de frutas e hortaliças, até a produção de farinha de mandioca.

O trabalho realizado em conjunto com a cooperativa foi desenvolvido pelo Núcleo de Gestão de Design (NGD) ${ }^{2}$ da Universidade Federal de Santa Catarina (UFSC) e contou com o apoio da EPAGRI, CNPq ${ }^{3}$ e FAPESC. Inicialmente, seguindo o observado no GODP em sua fase de inspiração, partindo da etapa que visa definir oportunidades, foi realizado um levantamento de dados preliminares que permitiu identificar algumas fragilidades da cooperativa em questão, caracterizadas por dependências econômicas no processo de produção, assim como dificuldades na comercialização de seus produtos. Quanto à dificuldade na 2 O site do NGD é: < $\langle$ http://www.ngd.ufsc.br/>.

3 O projeto foi desenvolvido com recursos provenientes do edital PROSUL. 
comercialização, pode-se relacionar tal questão à dificuldade existente na identificação dos produtos da cooperativa, embalados de maneira quase artesanal, sem apresentar cuidados quanto à manutenção de uma unidade visual ou até mesmo acerca de normas estabelecidas pela Agência Nacional de Vigilância Sanitária (ANVISA).

Após o trabalho realizado pela equipe do Núcleo de Gestão de Design, foi diagnosticada a necessidade da criação de uma marca coletiva, que, segundo o INPI (2011), "visa identificar produtos ou serviços provenientes de membros de um determinado grupo ou entidade". Dessa forma, desenvolveu-se a nova assinatura visual da COOPERLAGOS, como mostra a Figura 2.

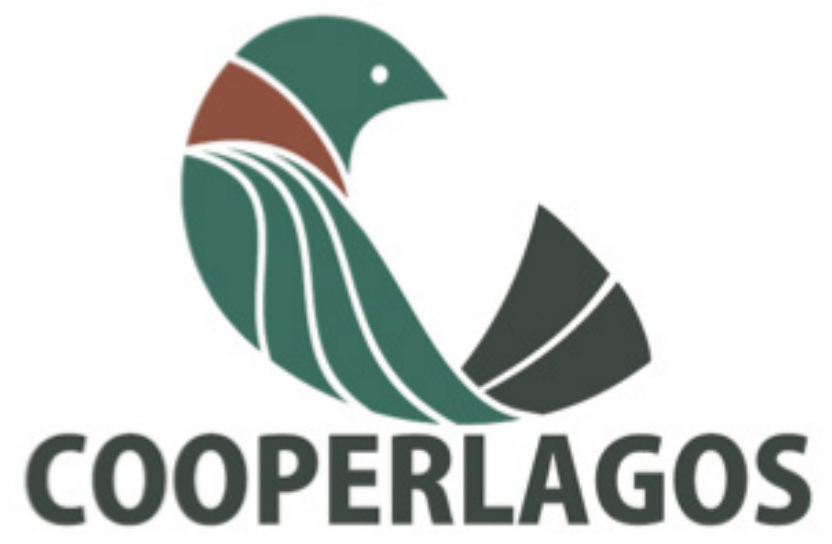

Figura 2 - Nova marca da COOPERLAGOS Fonte: Acervo NGD (2011).

Na Figura 3, visualiza-se a atual família de produtos derivados da mandioca da empresa, entre os quais a embalagem de $1 \mathrm{~kg}$ de farinha de mandioca, já disponível no mercado.

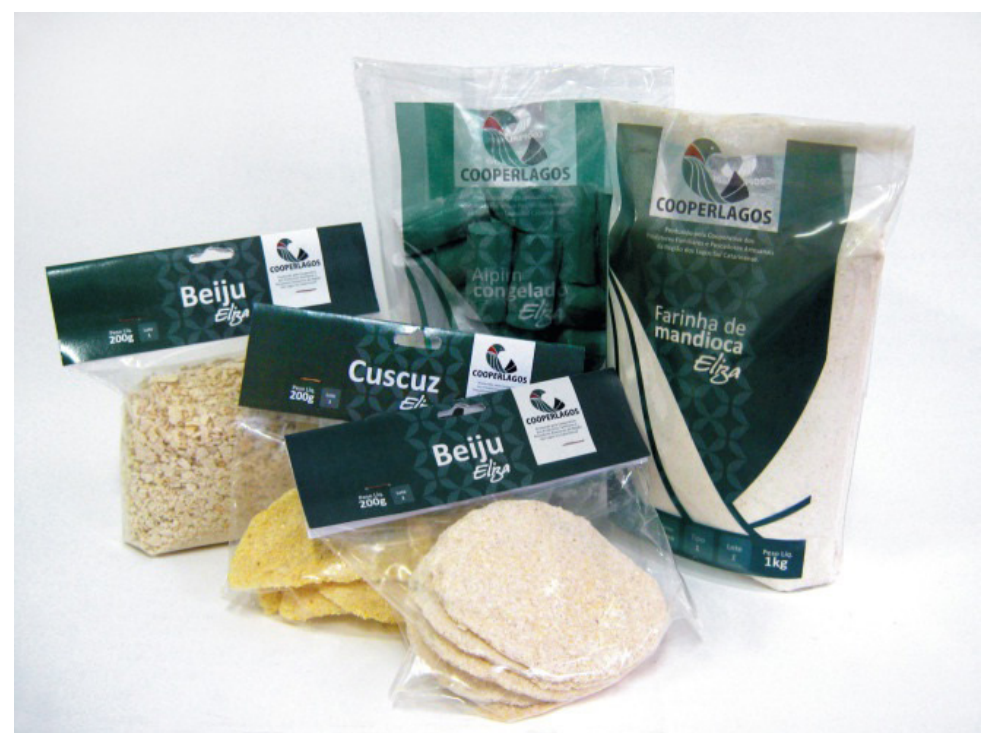

Figura 3 - Embalagens da cooperativa após a nova identidade visual Fonte: Acervo NDG (2011).

Tendo em conta as diretrizes propostas no trabalho intitulado "Farinha premium: farinha de mandioca em embalagem para ser levada à mesa” (MERINO et al., 2010), desenvolvido no Programa de Pós-Graduação em Engenharia de Produção da Universidade Federal de Santa Catarina, definiu-se que o produto a 


\section{Extensio $\mid$ Relato de Experiência}

ser desenvolvido deveria constituir uma embalagem ergonômica, com descrição detalhada do produto que acondiciona e possibilidade de refilamento, constituindo a etapa de prospeç̧ão, de acordo com o GODP.

Objetivando um embasamento teórico que justificasse o desenvolvimento e eventual comercialização da nova embalagem, a equipe coletou dados, consolidando uma série de informações quanto à importância econômica e cultural da mandioca, em particular no Brasil, onde os povos nativos brasileiros foram responsáveis pela domesticação e posterior processamento do alimento, cujos derivados produzidos foram descritos por Pero Vaz de Caminha em carta enviada ao rei de Portugal como sendo "tão alvos e saborosos que superam em muito o pão desse reino" (EMBRAPA, 2012).

Segundo dados de 2010 do Instituto Brasileiro de Geografia e Estatística (IBGE, 2010), prevê-se, para o ano de 2011, uma produção de 27,1 milhões de toneladas de mandioca. Em um contexto mundial, o Brasil situa-se em sétimo lugar quanto à produção de mandioca (FAO, 2011). A produção no país distribui-se da seguinte maneira entre as regiões do país: Nordeste, 37,18\%; Norte, 28,16\%; Sul, 19,97\%; Sudeste, 9,06\%; e Centro-Oeste, 5,61\%. Nesse cenário, o estado de Santa Catarina é reconhecido como "o berço da industrialização da mandioca no país" (AGROSOFT, 2008), apresentando, segundo dados de 2009 do IBGE, elevada produtividade, com uma produção de $18.367 \mathrm{~kg}$ por hectare (FAO, 2011).

No cenário catarinense, destaca-se ainda o avanço dos investimentos na adoção de um sistema de produção integrada da mandioca, incentivados pelo esforço conjunto da EPAGRI e da EMBRAPA visando à "[...] constituição de um processo contínuo e participativo, envolvendo os atores da cadeia produtiva da mandioca, onde se discutam os problemas e estabeleçam alternativas para sua solução [...]” (EMBRAPA, 2011).

A partir dos dados previamente coletados, pôde-se fazer a sua compilação e análise, de maneira que pudessem servir de base para o projeto aqui apresentado. Denota-se que uma parte importante dos dados coletados na pesquisa supracitada resultou da aplicação de um questionário on-line que visava à obtenção de informações quanto aos padrões de consumo da farinha de mandioca e quanto à percepção de consumidores em potencial perante o produto e a importância de sua embalagem, tendo-se extraído desse questionário, sobretudo das respostas dadas às perguntas abertas, informações de grande valia para o prosseguimento do projeto.

Na sequência, desenvolveu-se uma detalhada busca por referências e similares, coletando informações e imagens provindas das mais diversas fontes. Construiu-se, assim, um banco de referências, constituído por embalagens e variados produtos, ainda que nem sempre diretamente relacionados ao produto e ao uso a que se destinariam as soluções resultantes deste projeto. Denota-se a importância da construção de tal banco para a posterior utilização durante a etapa de geração de alternativas, constituindo, assim, uma interessante fonte de referências estéticas, formais, utilitárias e históricas.

Após o levantamento e organização dos dados, pôde-se iniciar a etapa criativa do processo, que se caracterizou pela geração de 32 alternativas diferentes de embalagem com tampa dosadora para farinha de mandioca. Por meio das alternativas geradas, buscou-se sintetizar os anseios básicos estabelecidos no projeto, sendo tais anseios caracterizados por questões tanto de ordem prática (referentes ao consumo da farinha de mandioca) quanto de ordem simbólica (referentes à importância histórica e cultural da mandioca). Dessa maneira, as alternativas compreenderam desde questões meramente relacionadas à estética quanto a questões funcionais e ergonômicas.

Com o processo de geração de alternativas finalizado, deu-se segmento ao projeto por meio de um processo de síntese das alternativas geradas. Tal etapa caracterizou-se pelo detalhamento das características positivas e negativas de cada uma das alternativas, cruzando tais dados com aqueles já obtidos referentes a questões como formas de consumo do produto, assim como preferências gerais do potencial consumidor. A equipe responsável pelo projeto realizou uma triagem das alternativas por meio da avaliação das suas características positivas e negativas.

Ademais, o processo de síntese avaliou as alternativas geradas quanto à sua capacidade de convergir as características de desejabilidade, praticabilidade e viabilidade, que definem, respectivamente, se o produto é 
capaz de suprir as necessidades e desejos do consumidor, se o produto é praticável, tanto em níveis técnicos quanto organizacionais, e se ele é financeiramente viável.

O processo de síntese resultou na escolha de três alternativas, cujos desenhos preliminares podem ser observados na Figura 4.

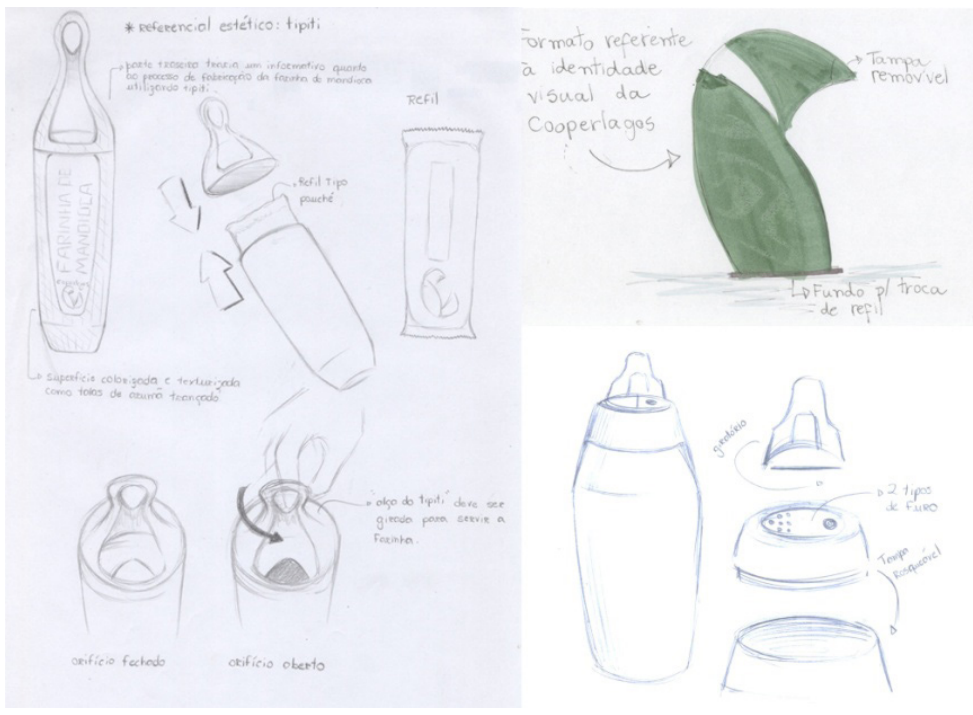

Figura 4 - Alternativa geradas

Fonte: Elaborado pelos autores (2011).

Em seguida, as alternativas geradas foram refinadas por meio de um melhor detalhamento delas. Definiram-se, de maneira mais precisa, como cada embalagem funcionaria e as partes que a comporiam. As alternativas foram reapresentadas sob a forma de desenhos detalhados.

A primeira das alternativas, visualizável na Figura 5, utiliza como referência estética e simbólica o tipiti, um instrumento essencial no preparo da farinha de mandioca, representado na Figura 6.

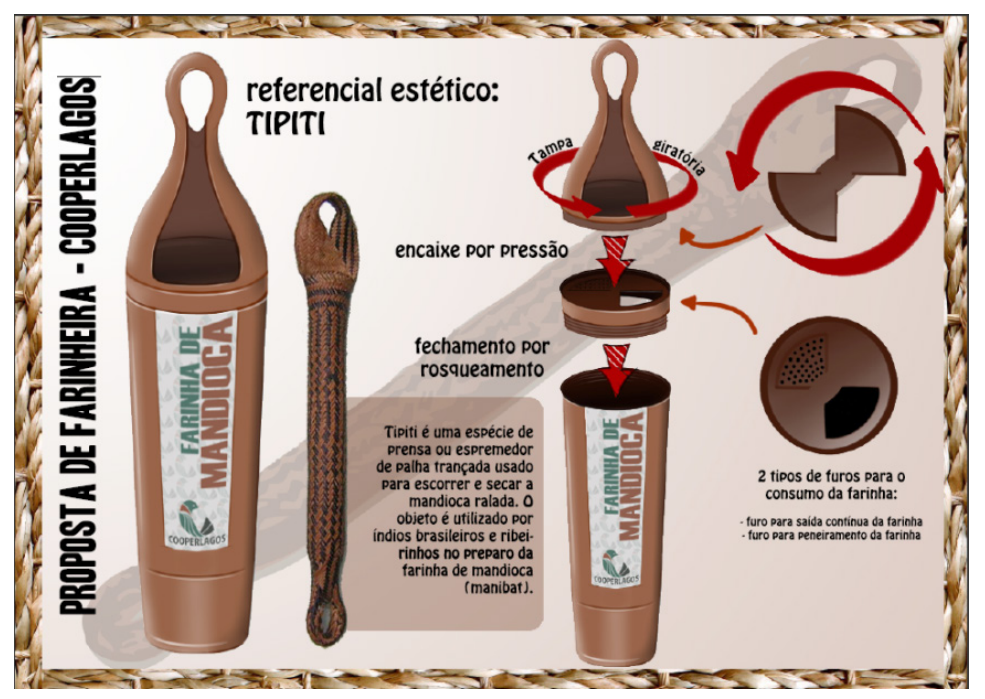

Figura 5 - Alternativa 1: referencial teórico tipiti Fonte: elaborado pelos autores (2011).

4 Espécie de espremedor de palha usado por diversos povos indígenas brasileiros para acelerar os processos de escorrimento e secagem da mandioca depois de ela já ter sido ralada (OBJETOS, 2011). 


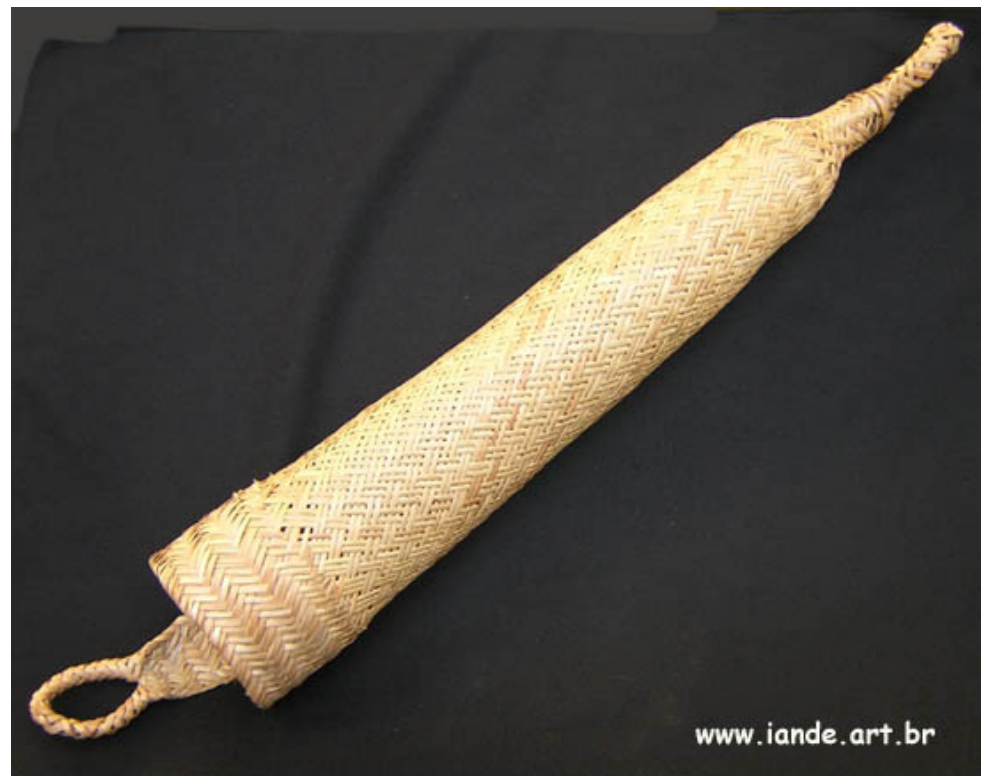

Figura 6 - Tipiti

Fonte: landé Casa das Culturas Indígenas (2011).

Tal alternativa apresenta uma tampa dosadora giratória com dois tipos de saídas para a farinha: uma delas é maior, permitindo a saída contínua da farinha, enquanto a outra é composta por uma série de furos menores que permitem o peneiramento. Permite ainda um posicionamento diferenciado nas gôndolas de supermercado, pendurando a embalagem por meio de sua argola.

A segunda alternativa, vista na Figura 7, também faz uso do tipiti como referência estética. Contudo, trata-se de uma interpretação mais estilizada e funcional de suas formas. Também apresenta um bico dosador giratório e dois tipos de saída para a farinha.

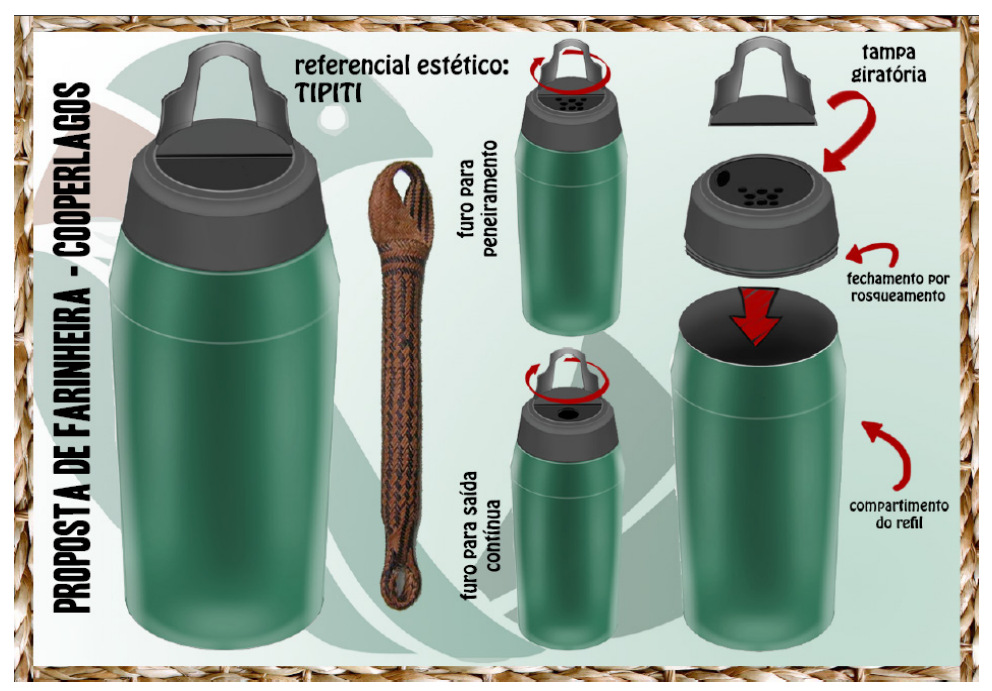

Figura 7 - Alternativa 2: representação digital Fonte: elaborado pelos autores (2011).

A terceira alternativa proposta, que pode ser observada na Figura 8, utiliza como referência estética a nova identidade da COOPERLAGOS, caracterizada pela junção das ilustrações de um peixe e de um pássaro. A tampa que cobre a superfície dosadora possui um sistema de abertura diferenciado, girando em seu próprio eixo por meio de um pino ligeiramente deslocado de seu centro. 


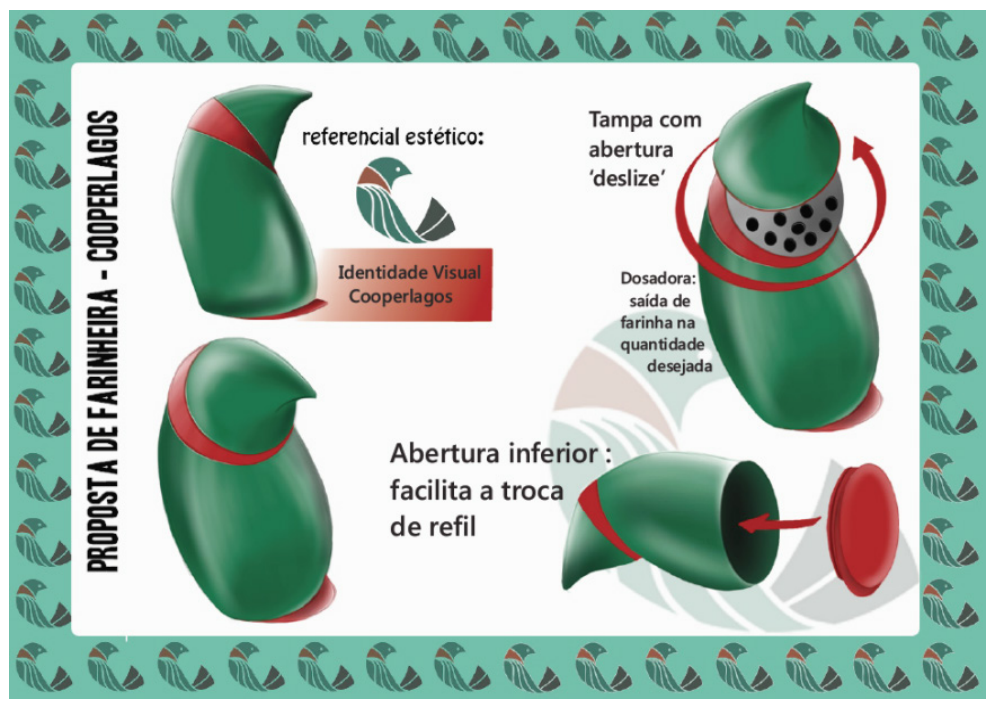

Figura 8 - Alternativa 3: representação digital Fonte: elaborado pelos autores (2011).

As três alternativas finais geradas remetem aos conceitos desejados, estando ligadas tanto à farinha de mandioca como à marca coletiva da cooperativa COOPERLAGOS. Além disso, seu projeto considerou satisfazer as necessidades dos possíveis consumidores finais, identificadas por meio da pesquisa realizada. Dessa maneira, entende-se que os resultados gerados tendam a contribuir para a valorização do grupo produtivo em questão, assim como do próprio produto comercializado.

Atualmente, o projeto encontra-se em fase de viabilização, de modo que, a partir das três alternativas finais geradas, foram efetuadas as requisições de patentes de modelo de utilidade, que se caracterizam por produtos que propõem melhorias substanciais para algo já disponível no mercado (INPI, 2011). Devido às restrições econômicas, ainda não se considera a produção de nenhuma das alternativas geradas, de modo que a participação dos cooperados tenderá a ocorrer de maneira ativa em uma possível etapa de viabilização do projeto.

\section{Considerações Finais}

Por meio da apresentação de exemplos concretos quanto à aplicação do design como meio de valorização da produção de grupos produtivos de pequeno porte, este artigo buscou evidenciar as capacidades transformadoras do design como ferramenta apta ao desenvolvimento de ações capazes de integrar objetivos e necessidades específicas de diversos produtores familiares, exaltando seus produtos e melhorando, por consequência, suas capacidades competitivas.

Tais melhorias são essenciais para que cooperativas como a que foi alvo de estudo neste artigo possam não apenas sobreviver, mas se tornar cada vez mais atuais e relevantes no cenário em que atuam, tornando-se mais competitivas ante grandes conglomerados do ramo alimentício. Denota-se ainda a importância da manutenção de uma estratégia de design adaptada à realidade de cada região, apropriando-se de uma visão capaz de enxergar o todo, porém atenta às necessidades específicas oriundas de certas realidades.

Destaca-se, em meio a todo o processo e atividades realizadas, a importância da aproximação da universidade em relação à sociedade, podendo suscitar em diversas oportunidades para ambas, tendo-se em conta os impactos positivos que uma equipe multidisciplinar de alunos pode fomentar, sejam estes provenientes de cursos de graduação ou pós-graduação, e até mesmo professores, que tenderão a obter diversos benefícios nas esferas acadêmica, profissional e até mesmo social. Ressalta-se aqui ainda a importância de 
instituições apoiadoras capazes de promover a manutenção dessa relação entre sociedade e universidade, por meio de atividades de extensão ou pesquisa.

A valorização do produto de pequenos produtores por meio da ação do design constitui um mercado de atuação ampla, contudo, pouco explorado, de maneira que se espera que ações pontuais como as apresentadas aqui possam servir de incentivo para novas abordagens.

\section{AGRADECIMENTOS}

Agradecemos à Pró-Reitoria de Extensão da Universidade Federal de Santa Catarina, ao CNPq e à FAPESC, cujos apoios foram imprescindíveis para a realização do projeto aqui apresentado.

\section{REFERÊNCIAS}

AGROSOFT. Epagri promove exposição sobre a história da mandioca em Santa Catarina. Disponível em: <http://www.agrosoft.org.br/agropag/101827.htm>. Acesso em: 05 out. 2011.

CUNHA, L. Embrapa comemora Dia da Mandioca. Raiz e Fruto Online, Cruz das Almas, Edição 6, abr. 2008. Disponível em: <http://www.cnpmf.embrapa.br/newsletter/ler_materia.php?codnoticia=74\&codedicao=14>. Acesso em: 05 mar. 2012.

EMBRAPA. Produção Integrada de Mandioca. Disponível em: <http://www.cnpmf.embrapa.br/ publicacoes/folder/Folder_Mandioca.pdf>. Acesso em: 05 out. 2011.

EPAGRI / CEPA (Santa Catarina). Síntese Anual da Agricultura de Santa Catarina. Florianópolis, 2009-2010.

FAO - FOOD AND AGRICULTURE ORGANIZATION OF THE UNITED NATIONS.

Commodities by country. Disponível em: <http://faostat.fao.org/site/339/default.aspx >. Acesso em: 24 out. 2011.

IANDÉ CASA DAS CULTURAS INDÍGENAS (São Paulo). Iandé Arte com História: a arte do Brasil feita em comunidades tradicionais . Disponível em: <http://www.iande.art.br/trancado/cozinha/waimirimatepi020802.htm>. Acesso em: 24 out. 2011.

IBGE. Levantamento Sistemático da Produção Agrícola. Disponível em: <http://www.ibge.gov.br/ home/presidencia/noticias/noticia_visualiza.php?id_noticia=1798\&id_pagina=1 >. Acesso em: 24 out. 2011.

INPI. Manual do Usuário: Sistema E-Marcas. Disponível em: <http://www.inpi.gov.br/downloads/ manual_usuario_emarcas.pdf>.Acesso em: 20 set. 2011.

MERINO, Eugenio Andrés Díaz. Projeto internacional de pesquisa: Valorização da produção de grupos produtivos de pequeno porte vinculados a sua origem, com base na competitividade, diferenciação e sustentabilidade. Relatório Final CNPq/FAPESC. Florianópolis: 2010. Universidade Federal de Santa Catarina. 
MERINO, Giselle; FERNADES, Carlos; GUELBERT, Tanatiana; P. DOS ANJOS, Thaiana; R.S. VALENTIM, Celso;.FARINHA PREMIUM: farinha de mandioca em embalagem para ser levada à mesa. Relatório de projeto. Florianópolis: 2010.

MERINO, Eugenio et al. Cadernos de Estudos Avançados em Design: Método. Barabacena: Editora da Universidade do Estado de Minas Gerais - Eduemg, 2011. 245 p.

MINISTÉRIO DA AGRICULTURA PECUÁRIA E ABASTECIMENTO (Org.). Manual de hortaliças não-convencionais. Disponível em: $<$ http://www.abcsem.com.br/docs/manual_hortalicas_web.pdf $>$. Acesso em: 20 set. 2011.

OBJETOS: Tipiti. Disponível em: <http://portalamazonia.globo.com/pscript/amazoniadeaaz/artigoAZ.php?idAz=400>. Acesso em: 29 ago. 2011. 